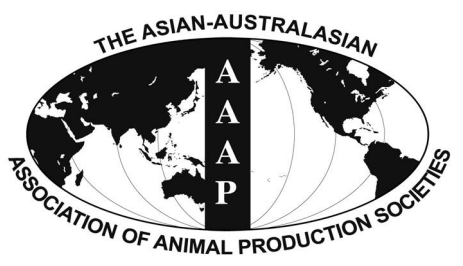

Open Access

Asian Australas. J. Anim. Sci.

Vol. 29, No. 10 : 1470-1476 October 2016

http://dx.doi.org/10.5713/ajas.15.0879

Www.ajas.info

pISSN 1011-2367 elSSN 1976-5517

\title{
Effects of Dietary Octacosanol on Growth Performance, Carcass Characteristics and Meat Quality of Broiler Chicks
}

\author{
L. Long ${ }^{1,2}$, S. G. Wu ${ }^{1}$, F. Yuan ${ }^{2}$, J. Wang ${ }^{1}$, H. J. Zhang ${ }^{1}$, and G. H. Qi ${ }^{1, *}$ \\ ${ }^{1}$ Key Laboratory of Feed Biotechnology of Ministry of Agriculture, Feed Research Institute, \\ Chinese Academy of Agricultural Sciences, Beijing 100081, China
}

\begin{abstract}
Octacosanol, which has prominent physiological activities and functions, has been recognized as a potential growth promoter in animals. A total of 392 1-d-old male Arbor Acres broiler chicks with similar body weight were randomly distributed into four dietary groups of seven replicates with 14 birds each supplemented with $0,12,24$, or $36 \mathrm{mg}$ octacosanol (extracted from rice bran, purity $>92 \%$ ) $/ \mathrm{kg}$ feed. The feeding trial lasted for six weeks and was divided into the starter (day 1 to 21 ) and the grower (day 22 to 42 ) phases. The results showed that the feed conversion ratio (FCR) was significantly improved in broilers fed a diet containing $24 \mathrm{mg} / \mathrm{kg}$ octacosanol compared with those fed the control diet in the overall phase (day 1 to $42, \mathrm{p}=0.042$ ). The average daily gain and FCR both showed linear effects in response to dietary supplementation of octacosanol during the overall phase $(\mathrm{p}=0.031$ and 0.018 , respectively). Broilers fed with 24 or $36 \mathrm{mg} / \mathrm{kg}$ octacosanol diet showed a higher eviscerated yield, which increased by $5.88 \%$ and $4.26 \%$ respectively, than those fed the control diet $(\mathrm{p}=0.030)$. The breast muscle yield of broilers fed with $24 \mathrm{mg} / \mathrm{kg}$ octacosanol diet increased significantly by $12.15 \%$ compared with those fed the control diet $(\mathrm{p}=0.047)$. Eviscerated and breast muscle yield increased linearly with the increase in dietary octacosanol supplementation ( $\mathrm{p}=0.013$ and 0.021 , respectively). Broilers fed with 24 or $36 \mathrm{mg} / \mathrm{kg}$ octacosanol diet had a greater $(\mathrm{p}=0.021) \mathrm{pH}_{45 \min }$ value in the breast muscle, which was maintained linearly in response to dietary octacosanol supplementation $(p=0.003)$. There was a significant decrease $(p=0.007)$ in drip loss value between the octacosanol-added and the control groups. The drip loss showed linear $(p=0.004)$ and quadratic $(p=0.041)$ responses with dietary supplementation of octacosanol. These studies indicate that octacosanol is a potentially effective and safe feed additive which may improve feed efficiency and meat quality, and increase eviscerated and breast muscle yield, in broiler chicks. Dietary supplementation of octacosanol at $24 \mathrm{mg} / \mathrm{kg}$ diet is regarded as the recommended dosage in the broilers' diet. (Key Words: Octacosanol, Growth Performance, Carcass Characteristics, Meat Quality, Broiler Chick)
\end{abstract}

\section{INTRODUCTION}

Octacosanol ( $\left.\mathrm{HO}-\mathrm{CH}_{2}-\left[\mathrm{CH}_{2}\right]_{26} \mathrm{CH}_{3}\right)$, a long-chain aliphatic alcohol, is the main component of a natural wax product that exists in wheat germ oil, rice bran oil, fruits or leaves (Taylor et al., 2003; de Oliveira et al., 2012). Octacosanol has been reported to exhibit a variety of important biological activities in humans and rodents, including antifatigue properties (Kim et al., 2004), antioxidant activities (Ohta et al., 2008), cholesterol-

\footnotetext{
* Corresponding Author: G. H. Qi. Tel: +86-10-82107317, Fax:+86-10-82106054, E-mail: qiguanghai@caas.cn

${ }^{2}$ Tianjin Naer Biotechnology Co., Ltd., Tianjin 300457, China.

Submitted Oct. 26, 2015; Revised Mar. 19, 2016; Accepted Apr. 22, 2016
}

lowering effects (Hernandez et al., 1992), cytoprotective function (Carbajal et al., 1996) and ergogenic properties (Oliaro-Bosso et al., 2009). Studies have shown that the addition of dietary octacosanol has a beneficial effect on metabolic responses to submaximal cycle ergometry, grip and chest strength, and reaction time in human subjects (Saint-John and McNaughton, 1986), and has enhanced the running performance and related biochemical parameters in exercise-trained rats (Kim et al., 2004). Other studies on the effects of octacosanol on lipid metabolism have revealed that the addition of octacosanol leads to a significant decrease in the weight of perirenal adipose tissue of high-fat diet rats (Taylor et al., 2003) and reduces low-density lipoprotein (LDL), triacylglycerol and cholesterol content in 
the plasma of mice, healthy volunteers or patients (Aneiros et al., 1995; Menendez et al., 2000; Xu et al., 2007). Decreased cholesterol synthesis or enhanced LDL catabolism may be the mechanism of action here (GouniBerthold and Berthold, 2002). In terms of antioxidant function, octacosanol protects against $\mathrm{CCl}_{4}$-induced liver injury in rats by attenuating disrupted hepatic reactive oxygen species metabolism (Ohta et al., 2008), and inhibits in vitro copper ion-induced rat lipoprotein peroxidation (Menendez et al., 1999). In addition, cytoprotection and anti-inflammatory properties have also been confirmed (Carbajal et al., 1996; de Oliveira et al., 2012). Mixtures of long-chain aliphatic alcohols (e.g. policosanol, of which octacosanol is the main component) have been shown to exert similar effects (Arruzazabala et al., 1994; Singh et al., 2006). These studies on the physiological function of octacosanol or policosanol were mainly conducted on rodents or human volunteers.

In view of its prominent physiological functions and high level of safety, with $\mathrm{LD}_{50}>18,000 \mathrm{mg} / \mathrm{kg}$ (Pons et al., 1993), octacosanol has been widely applied to health food, functional beverage, medicine and other fields. Due to its versatile functions, octacosanol may be developed as a potential feed additive for domestic animals. In our previous study, we found that octacosanol increased the growth performance of weaning piglets (Long et al., 2015), which indicated that the addition of octacosanol was effective in animal production. The objective of this study was, therefore, to test the efficacy of dietary octacosanol supplementation on growth performance, carcass characteristics and meat quality in broiler chicks, offering the poultry industry a new direction.

\section{MATERIALS AND METHODS}

\section{Birds and management}

The animal protocol for the present study was approved by the Animal Care and Use Committee of Feed Research Institute of the Chinese Academy of Agricultural Sciences. A total of 392 1-d-old male Arbor Acres broiler chicks with similar body weight (BW) was obtained from the Beijing Huadu Broiler Company (Beijing, China). All chicks were housed in a standardized chicken house with double-floor cages containing a tube feeder, a nipple drinker line and built-up soft-wood shavings, and exposed to a $23 \mathrm{~h}$ of light for the first two weeks and $20 \mathrm{~h}$ of light thereafter. The initial temperature in the chicken house was $34^{\circ} \mathrm{C}$ for the first week and was reduced by $2^{\circ} \mathrm{C}$ each consecutive week until the temperature reached $24^{\circ} \mathrm{C}$. Relative humidity was set at $50 \%$ throughout the trial. Diets, in pellet form, and fresh water were supplied ad libitum, and ventilation was controlled. All management of broilers was in accordance with the recommendations of the Arbor Acres Broiler
Management Handbook (Aviagen Inc., 2014).

\section{Experimental design and the diets}

The broilers were randomly divided into four groups with seven replicates of 14 birds each. Broilers were fed with a basal diet (Table 1) supplemented with $0,12,24$, or $36 \mathrm{mg}$ octacosanol $/ \mathrm{kg}$ diet. Octacosanol (purity $>92 \%$ ), extracted from rice bran, was provided by the Huzhou Shuanglin Shengtao Vegetable Oil Factory (Zhejiang, China). Basal diets, divided into two phases according to the ages of the chicks (starter phase, 1 to $21 \mathrm{~d}$; grower phase, 22 to $42 \mathrm{~d}$ ), were formulated according to the NRC (1994) and the Chinese Feeding Standard of Chicken (Ministry of Agriculture of China, 2004).

\section{Growth performance}

The data relating to the BW and feed intake of the chicks during the starter phase (d 1 to 21 ) and the grower phase (d 22 to 42) were recorded. The average daily gain (ADG), average daily feed intake (ADFI) and feed conversion ratio (FCR, the ratio of feed to gain) were calculated for each period and cumulatively. These

Table 1. Dietary composition and nutrient levels of the basal diets (as-fed basis)

\begin{tabular}{lcc}
\hline & $\begin{array}{c}\text { Starter phase } \\
\text { (d 1 to 21) }\end{array}$ & $\begin{array}{c}\text { Grower phase } \\
\text { (d 22 to 42) }\end{array}$ \\
\hline Ingredient (\%) & 60.80 & 63.90 \\
Corn & 32.90 & 28.95 \\
Soybean meal & 2.00 & 3.00 \\
Soybean oil & 1.62 & 1.50 \\
Dicalcium phosphate & 1.55 & 1.60 \\
Limestone & 0.36 & 0.36 \\
Salt & 0.23 & 0.16 \\
DL-methionine & 0.25 & 0.24 \\
L-lysine·HCl & 0.29 & 0.29 \\
Vitamin-mineral premix ${ }^{1}$ & 100.00 & 100.00 \\
Total & & \\
Nutrient level ${ }^{2}$ & 12.12 & 12.50 \\
AME (MJ/kg) & $20.30(20.85)$ & $18.56(18.02)$ \\
CP (\%) & $0.96(1.02)$ & $0.94(0.86)$ \\
Ca (\%) & $0.64(0.68)$ & $0.60(0.62)$ \\
Total P (\%) & 0.41 & 0.39 \\
Available P (\%) & 1.10 & 1.00 \\
Lysine $(\%)$ & 0.52 & 0.41 \\
Methionine (\%) & 0.83 & 0.72 \\
Methionine+cysteine $(\%)$ &
\end{tabular}

AME, apparent metabolizable energy; $\mathrm{CP}$, crude protein.

${ }^{1}$ Supplied per kg diet: vitamin A, 12,500 IU; vitamin $\mathrm{D}_{3}, 2,500 \mathrm{IU}$; vitamin $\mathrm{E}, 15 \mathrm{IU}$; vitamin $\mathrm{K}_{3}, 2.5 \mathrm{mg}$; vitamin $\mathrm{B}_{1}, 3.2 \mathrm{mg}$; vitamin $\mathrm{B}_{2}$, $6.5 \mathrm{mg}$; vitamin $\mathrm{B}_{12}, 0.025 \mathrm{mg}$; nicotinic acid, $30 \mathrm{mg}$; calcium pantothenate, $12 \mathrm{mg}$; biotin, $0.03 \mathrm{mg}$; folic acid, $1.0 \mathrm{mg}$; iron, $80 \mathrm{mg}$; copper, $8 \mathrm{mg}$; manganese, $100 \mathrm{mg}$; zinc, $75 \mathrm{mg}$; iodine, $0.35 \mathrm{mg}$; and selenium, $0.15 \mathrm{mg}$.

2 The value in parentheses indicates the analyzed value. Others are calculated values. 
parameters were corrected according to mortality.

\section{Carcass characteristics}

On the last day of the experiment, two chicks were selected from each replicate and killed after a $12 \mathrm{~h}$ fasting for slaughter mensuration. The sacrificed chicks were exsanguinated and deplumed immediately. Next, the eviscerated weight and the internal organ weight of the heart, liver and spleen were measured. Breast muscles (including pectoralis major and minor), leg muscles (including thigh and drumstick muscles) and abdominal fat (including leaf fat surrounding the cloaca and abdominal fat surrounding the gizzard) were removed and weighed. Eviscerated yield, breast muscle yield, leg muscle yield, abdominal fat percentage and relative internal organ weight were all calculated as percentages of BW. The average value of the two broilers was regarded as the replicate value.

\section{Meat quality}

The qualities of the breast muscle were evaluated. The meat colour at three points of a meat piece was measured with a spectrocolorimeter (Minolta-CR200, Tokyo, Japan) at $45 \mathrm{~min}$ after slaughter. The meat quality was evaluated according to the Commission Internationale de L'Eclairage (CIE) $\mathrm{L}^{*} \mathrm{a} * \mathrm{~b} *$ coordinates (where $\mathrm{L}^{*}$ indicates relative lightness, $\mathrm{a}^{*}$ indicates relative redness, and $\mathrm{b}^{*}$ indicates relative yellowness). At the same time, the $\mathrm{pH}$ values at a depth of $2.5 \mathrm{~cm}$ below the surface for each sample were measured at $45 \mathrm{~min}$, as initial $\mathrm{pH}$, and at $24 \mathrm{~h}$, as ultimate $\mathrm{pH}$, after slaughter using a $\mathrm{pH}$ meter (Star A, Thermo Fisher Scientific, Waltham, MA, USA). Next, drip loss was measured using approximately $2 \mathrm{~g}$ of breast muscle sample according to the method described by Honikel (1998).

\section{Statistical analysis}

All data were performed using SPSS 17.0 for Windows software and expressed as mean values with pooled standard errors of the means using one-way analysis of variance. The difference between group means was separated by the least significant difference (Duncan's) multiple range test. The dose-response effect of supplemental octacosanol was computed using orthogonal polynomial contrast for linear and quadratic effects. Differences were considered statistically significant at $\mathrm{p}<0.05$ unless otherwise stated.

\section{RESULTS}

\section{Growth performance}

The results of growth performance of broilers are presented in Table 2. No significant differences in growth performance were observed between the octacosanol-added and control groups during the starter phase (d 1 to 21 , $\mathrm{p}>0.05$ ). In the grower phase (d 22 to 42), dietary supplementation of octacosanol improved BW and FCR compared with the control group, and BW increased linearly $(\mathrm{p}=0.031)$ with dietary supplementation of octacosanol, while FCR decreased linearly $(\mathrm{p}=0.016)$. During the overall phase (d 1 to 42 ), chicks fed with 24 $\mathrm{mg} / \mathrm{kg}$ octacosanol diet showed comparably lower FCR, which decreased by $5.17 \%$, compared with those fed the control diet $(p=0.042)$. Average daily gain and FCR both

Table 2. Effect of dietary octacosanol supplementation on growth performance of broilers ${ }^{1}$

\begin{tabular}{|c|c|c|c|c|c|c|c|c|}
\hline \multirow{2}{*}{ Items } & \multicolumn{4}{|c|}{ Dietary octacosanol addition $(\mathrm{mg} / \mathrm{kg})$} & \multirow{2}{*}{ Pooled SEM - } & \multicolumn{3}{|c|}{ p-value } \\
\hline & 0 & 12 & 24 & 36 & & $\mathrm{ANOVA}^{2}$ & Linear $^{3}$ & Quadratic $^{3}$ \\
\hline \multicolumn{9}{|l|}{ Starter phase (d 1 to 21$)$} \\
\hline BW d $21(\mathrm{~g})$ & 729 & 725 & 740 & 731 & 3.22 & 0.450 & 0.458 & 0.719 \\
\hline $\mathrm{ADG}(\mathrm{g})$ & 32.62 & 32.44 & 33.14 & 32.74 & 0.15 & 0.445 & 0.453 & 0.716 \\
\hline ADFI $(g)$ & 48.83 & 48.07 & 48.39 & 49.28 & 0.52 & 0.874 & 0.742 & 0.458 \\
\hline FCR (feed:gain, g:g) & 1.496 & 1.483 & 1.460 & 1.506 & 0.02 & 0.815 & 0.964 & 0.414 \\
\hline \multicolumn{9}{|l|}{ Grower phase (d 22 to 42 ) } \\
\hline BW d $42(\mathrm{~g})$ & 2,272 & 2,310 & 2,351 & 2,339 & 12.52 & 0.114 & 0.031 & 0.302 \\
\hline $\mathrm{ADG}(\mathrm{g})$ & 73.50 & 75.47 & 76.71 & 76.55 & 0.61 & 0.222 & 0.060 & 0.374 \\
\hline ADFI (g) & 144.95 & 145.67 & 142.29 & 144.04 & 0.69 & 0.349 & 0.325 & 0.709 \\
\hline FCR (feed:gain, g:g) & 1.973 & 1.935 & 1.857 & 1.877 & 0.02 & 0.061 & 0.016 & 0.370 \\
\hline \multicolumn{9}{|l|}{ Whole phase ( 11 to 42 ) } \\
\hline $\mathrm{ADG}(\mathrm{g})$ & 53.07 & 53.96 & 54.94 & 54.64 & 0.30 & 0.111 & 0.031 & 0.298 \\
\hline ADFI (g) & 96.90 & 96.86 & 95.34 & 96.41 & 0.39 & 0.486 & 0.409 & 0.488 \\
\hline FCR (feed:gain, g:g) & $1.829^{\mathrm{b}}$ & $1.796^{\mathrm{ab}}$ & $1.737^{\mathrm{a}}$ & $1.764^{\mathrm{ab}}$ & 0.01 & 0.042 & 0.018 & 0.188 \\
\hline
\end{tabular}

SEM, standard error of the mean; ANOVA, analysis of variance; BW, body weight; ADG, average daily gain; ADFI, average daily feed intake; FCR, feed conversion ratio.

${ }^{1} \mathrm{n}=7$ per treatment, with 14 broilers per replicate. ${ }^{2}$ One-way ANOVA of all treatment groups.

${ }^{3}$ Linear and quadratic effects of increasing inclusion levels of octacosanol.

${ }^{a, b}$ Values within a row with different superscript letters are significantly different $(p<0.05)$. 
Table 3. Effect of dietary octacosanol supplementation on carcass characteristics of broilers at d $42^{1}$

\begin{tabular}{lcccccccc}
\hline \multirow{2}{*}{ Items $^{2}$} & \multicolumn{3}{c}{ Dietary octacosanol addition $(\mathrm{mg} / \mathrm{kg}$ feed } & \multirow{2}{*}{ Pooled SEM } & \multicolumn{3}{c}{$\mathrm{p}$-value } \\
\cline { 2 - 7 } & 0 & 12 & 24 & 36 & & ANOVA $^{3}$ & Linear $^{4}$ & Quadratic $^{4}$ \\
\hline Eviscerated yield (\%) & $70.70^{\mathrm{b}}$ & $72.55^{\mathrm{ab}}$ & $74.86^{\mathrm{a}}$ & $73.71^{\mathrm{a}}$ & 0.54 & 0.030 & 0.013 & 0.126 \\
Breast muscle yield (\%) & $18.03^{\mathrm{b}}$ & $19.11^{\mathrm{ab}}$ & $20.22^{\mathrm{a}}$ & $19.62^{\mathrm{ab}}$ & 0.29 & 0.047 & 0.021 & 0.126 \\
Leg muscle yield (\%) & 15.98 & 16.54 & 16.86 & 16.34 & 0.24 & 0.662 & 0.543 & 0.293 \\
Abdominal fat (\%) & 1.77 & 1.73 & 1.70 & 1.70 & 0.01 & 0.201 & 0.048 & 0.437 \\
Heart weight (g/kg BW) & 4.92 & 4.66 & 4.51 & 4.99 & 0.08 & 0.098 & 0.929 & 0.081 \\
Liver weight (g/kg BW) & 16.19 & 16.56 & 16.37 & 16.82 & 0.19 & 0.702 & 0.340 & 0.911 \\
Spleen weight (g/kg BW) & 1.05 & 1.06 & 1.04 & 1.09 & 0.01 & 0.562 & 0.445 & 0.557 \\
\hline
\end{tabular}

SEM, standard error of the mean; ANOVA, analysis of variance; BW, body weight.

${ }^{1} \mathrm{n}=7$ per treatment, with 2 birds per replicate. ${ }^{2}$ All the indicators were calculated as percentage of BW.

${ }^{3}$ One-way ANOVA of all treatment groups. ${ }^{4}$ Linear and quadratic effects of increasing inclusion levels of octacosanol.

${ }^{a, b}$ Values within a row with different superscript letters are significantly different $(p<0.05)$.

showed linear effects in response to dietary addition of octacosanol during the overall phase $(\mathrm{p}=0.031$ and 0.018 , respectively). No significant difference was observed in ADFI among all groups $(\mathrm{p}>0.05)$.

\section{Carcass characteristics}

The effect of dietary supplementation of octacosanol on the carcass characteristics of broilers is presented in Table 3. Broilers fed with dietary supplemental 24 or $36 \mathrm{mg} / \mathrm{kg}$ octacosanol showed higher eviscerated yield, which increased by $5.88 \%$ and $4.26 \%$ respectively, than those fed the control diet $(\mathrm{p}=0.030)$. Compared with the control group, breast muscle yield of the broilers was significantly increased by $12.15 \%$ when the broilers were fed with 24 $\mathrm{mg} / \mathrm{kg}$ octacosanol diet $(\mathrm{p}=0.047)$. There was a linear increase in eviscerated $(\mathrm{p}=0.013)$ and breast muscle yield $(\mathrm{p}=0.021)$ with the dietary addition of octacosanol. No differences were observed in leg muscle yield and abdominal fat percentage among different groups ( $p>0.05)$. However, the abdominal fat content decreased linearly in response to dietary octacosanol supplementation (linear effect, $p=0.048$ ). No significant differences were found in the heart, liver or spleen weight among all groups ( $p>0.05)$.

\section{Meat quality}

Broilers fed with the 24 or $36 \mathrm{mg} / \mathrm{kg}$ octacosanol diets had a higher $\mathrm{pH}_{45 \min }$ value $(\mathrm{p}=0.021)$ in the breast muscle, which remained higher linearly - in response to the dietary addition of octacosanol $(p=0.003)$ - than those fed the control diet (Table 4). No differences were observed in $\mathrm{pH}_{24 \mathrm{~h}}$ value among all treatments $(\mathrm{p}>0.05)$ or in $\mathrm{L}^{*}, \mathrm{a}^{*}$, or $b^{*}$ value among all treatments $(p>0.05)$. However, the $a^{*}$ value increased linearly in response to dietary octacosanol supplementation (linear effect, $\mathrm{p}=0.051$ ). In addition, a significant difference $(p=0.007)$ in drip loss was observed between the octacosanol-added groups and the control group. Compared with the control diet, the chicken drip loss decreased by $2.97 \%, 5.03 \%$, and $3.89 \%$, which showed linear $(\mathrm{p}=0.004)$ and quadratic $(\mathrm{p}=0.041)$ effects with dietary supplementation of octacosanol.

\section{DISCUSSION}

Octacosanol or policosanol is considered to be a safe agent (Arruzazabala et al., 1994). As it is an additive, the effect on the growth performance of animals is the most valuable index. This study revealed that the dietary addition of octacosanol improved the growth performance of broiler

Table 4. Effect of dietary octacosanol supplementation on meat quality of broilers at $\mathrm{d} 42^{1}$

\begin{tabular}{|c|c|c|c|c|c|c|c|c|}
\hline \multirow{2}{*}{ Items } & \multicolumn{4}{|c|}{ Dietary octacosanol addition (mg/kg feed) } & \multirow{2}{*}{ Pooled SEM } & \multicolumn{3}{|c|}{ p-value } \\
\hline & 0 & 12 & 24 & 36 & & $\mathrm{ANOVA}^{2}$ & Linear $^{3}$ & Quadratic $^{3}$ \\
\hline $\mathrm{pH}_{45 \min }^{4}$ & $6.04^{b}$ & $6.13^{\mathrm{ab}}$ & $6.15^{\mathrm{a}}$ & $6.20^{\mathrm{a}}$ & 0.02 & 0.021 & 0.003 & 0.560 \\
\hline $\mathrm{pH}_{24 \mathrm{~h}}^{4}$ & 5.72 & 5.72 & 5.70 & 5.79 & 0.02 & 0.345 & 0.261 & 0.243 \\
\hline Lightness $\left(\mathrm{L}^{*}\right)$ & 57.29 & 57.34 & 57.18 & 57.69 & 0.11 & 0.434 & 0.312 & 0.318 \\
\hline Redness $\left(\mathrm{a}^{*}\right)$ & 13.78 & 14.34 & 14.76 & 14.42 & 0.14 & 0.083 & 0.051 & 0.095 \\
\hline Yellowness $\left(b^{*}\right)$ & 14.70 & 14.51 & 14.43 & 15.00 & 0.18 & 0.698 & 0.623 & 0.308 \\
\hline Drip $\operatorname{loss}^{5}(\%)$ & $4.37^{\mathrm{B}}$ & $4.24^{\mathrm{A}}$ & $4.15^{\mathrm{A}}$ & $4.20^{\mathrm{A}}$ & 0.02 & 0.007 & 0.004 & 0.041 \\
\hline
\end{tabular}

SEM, standard error of the mean; ANOVA, analysis of variance.

${ }^{1} \mathrm{n}=7$ per treatment, with 2 birds per replicate. ${ }^{2}$ One-way ANOVA of all treatment groups.

${ }^{3}$ Linear and quadratic effects of increasing inclusion levels of octacosanol. ${ }^{4} \mathrm{pH}_{45 \mathrm{~min}}, 45$ min postmortem; $\mathrm{pH}_{24 \mathrm{~h}}, 24 \mathrm{~h}$ postmortem.

${ }^{5}$ Measured when hung at $48 \mathrm{~h}$.

${ }^{a, b}$ Values within a row with different superscript letters are significantly different $(p<0.05)$.

${ }^{\mathrm{A}, \mathrm{B}}$ Values within a row with different superscript letters differ significantly $(\mathrm{p}<0.01)$. 
chicks and that the dietary addition of octacosanol at 24 $\mathrm{mg} / \mathrm{kg}$ diet showed the best feed efficiency during the overall period. $\mathrm{Xu}$ and Shen (1997) obtained the same results by supplementing the diet of broiler chicks with 25 $\mathrm{mg} / \mathrm{kg}$ octacosanol for 42 days. In addition, the study by $\mathrm{Xu}$ et al. (2007) reported that a $1 \%$ octacosanol (wt/wt) diet group of $\mathrm{E}-\mathrm{KO}$ mice gained weight at a rate comparable with the control group, while the study by Xiang et al. (2012) revealed that moderate doses of octacosanol in rats effectively increase the ADFI and ADG, and improve feed efficiency. These results support the hypothesis that octacosanol may improve the growth performance of domestic animals.

Other studies have shown that dietary octacosanol supplementation effectively promotes the secretion of growth hormone $(\mathrm{GH})$ in the blood of rats (Yang, 2012), which can promote protein deposition and bone growth by regulating metabolic processes and energy metabolism in the body (Brown-Borg and Bartke, 2012). Moreover, octacosanol is effective in modulating lipid metabolism, in enhancing glycogen storage, and in decreasing the rate of glycogen utilization in muscle (Kato et al., 1995; Kim et al., 2004), which is due in part to increased energy metabolism through the activation of adenosine monophosphateactivated protein kinase (AMPK) in the muscle (OliaroBosso et al., 2009). These findings indicate that octacosanol may potentially be used as an ergogenic agent. Accordingly, one possible reason for the improvement in the broilers' growth performance with octacosanol is the resulting increase in GH levels in the chicks along with an enhanced rate of glycogen utilization for growth (Kim et al., 2004). Further research is needed to clarify the effect of octacosanol on GH in broilers' blood and the efficacy of octacosanol as an ergogenic compound.

To our knowledge, the effects of dietary supplementation of octacosanol on carcass characteristics have not yet been reported. In our current study, octacosanol improved the eviscerated yield and breast muscle yield of broilers. Moreover, it led to a decrease in abdominal fat content. Octacosanol was also shown to be effective in improving the carcass characteristics of broilers.

In fast-growing broilers, growth occurs primarily in the pectorals and feathers during the late stages of development (Scheele, 1997). The relative increase in growth in octacosanol-fed chicks in the grower phase may partly contribute to the comparable increase in breast muscle. Published studies have reported that octacosanol may stimulate the mRNA expression of glycogen synthase in muscle (Yang, 2012), which is effective in regulating glycogen supply and in maintaining the energy balance in muscle. The major metabolic consequences of adaptation to physical functions are a slower rate of muscle glycogen utilization and a greater reliance on fat oxidation in the muscle (Crowley et al., 1996). Thus, in our study, more energy and nutrients were directed towards growth, e.g. breast development, when octacosanol was added to the diet, which improved the feed utilization by broilers during the grower stage. In contrast, no effects on leg muscle yield were observed with dietary supplementation of octacosanol. This result may be explained by the different compositions of muscle fibre types, the rate of protein turnover (Baillie and Garlick, 1991) and the differences in chemical composition (Douris et al., 2006; Lavery et al., 2008) between the breast and leg muscles of animals. In addition, it has been reported that muscle growth factors are more effective in breast muscles than in leg muscles (Qiao et al., 2013). This effect of octacosanol on muscle tissues in broilers is worthy of follow-up investigation.

In the present study, the abdominal fat percentage decreased in response to the increase in octacosanol. Kato et al. (1995) also showed that dietary octacosanol supplementation significantly reduced the weight of perirenal adipose tissue in high-fat diet rats. Moreover, other studies have reported that the development of adipose tissue depends on the availability of serum lipids, which are principal substrates in lipid metabolism (Zhang et al., 2011; Liao et al., 2015). Accordingly, the decrease in abdominal fat content evoked by octacosanol supplementation may be associated with the effect of serum lipid metabolism and the inhibition of cholesterol synthesis (Shimura et al., 1987; Hernandez et al., 1992; Arruzazabala et al., 1994; Castano et al., 2000). Additional experiments are needed to confirm the effect of octacosanol on lipid metabolism.

Research into the influence of octacosanol on muscle qualities, such as fibre size, density, and transformation, remains limited. In this study, we investigated the effect of octacosanol on the meat quality of animals. It is demonstrated that the addition of octacosanol influences $\mathrm{pH}_{45 \min }, \mathrm{a}^{*}$ values and drip loss. Glycolysis - anaerobic metabolism initiated in post-mortem breast muscle-can produce lactic acid and lead to a reduction in meat $\mathrm{pH}$ (Cai et al., 2015), which will influence the colour and waterholding capacity of chicken. In addition, meat colour, which mainly depends on the content of the muscle myoglobin, is a comprehensive index reflecting muscle physiology and biochemical and microbiological changes. Drip loss is a sensitive index of muscle protein structure and charge change, which directly influence the flavour, tenderness, processing and storage of the muscle. An improvement in $\mathrm{pH}_{45 \mathrm{~min}}, \mathrm{a}^{*}$ values and drip loss results in improved quality. The mechanisms for the improvement in meat quality concomitant with dietary octacosanol supplementation remain unclear, but it has been presumed that the effect may be attributed to the antioxidant properties of octacosanol.

Some studies have suggested that preventing lipid peroxidation in intramuscular fat-which is rich in 
unsaturated fatty acids and easily oxidized, and has phospholipids as its main component-is beneficial to maintaining the quality and flavour of meat (McCormick, 1999; Chikunya et al., 2004; Kamboh and Zhu, 2013). Studies have confirmed that octacosanol can inhibit both liver and blood lipid oxidation (Ohta et al., 2008; Long et al., 2015) and protect lipoprotein particles against lipid peroxidation in animals (Menendez et al., 1999; Yu, 2003). Therefore, one reason for the improvement in meat quality produced by octacosanol may be the antioxidant effect. The exact mechanism, however, needs further elucidation.

\section{CONCLUSION}

In summary, the results of the present study indicate that octacosanol is an effective and safe feed additive as it can improve feed efficiency, stimulate eviscerated yield and breast muscle yield, and contribute to good meat quality. In this study, dietary supplementation of octacosanol at 24 $\mathrm{mg} / \mathrm{kg}$ was regarded as the recommended dosage in the diet of broilers.

\section{CONFLICT OF INTEREST}

We certify that there is no conflict of interest with any financial organization regarding the material discussed in the manuscript.

\section{ACKNOWLEDGMENTS}

The financial support provided by the China Agriculture Research System-Beijing Team for Poultry Industry and the Agricultural Science and Technology Innovation Program (ASTIP) is gratefully appreciated.

\section{REFERENCES}

Aneiros, E., R. Mas, B. Calderon, J. Illnait, L. Fernandez, G. Castano, and J. C. Fernandez. 1995. Effects of policosanol in lowering cholesterol levels in patients with type II hypercholesterolemia. Curr. Ther. Res. 56:176-182.

Arruzazabala, M. L., D. Carbajal, R. Mas, V. Molina, S. Valdes, and A. Laguna. 1994. Cholesterol-lowering effects of policosanol in rabbits. Biol. Res. 27:205-208.

Aviagen Inc. 2014. Arbor Acres Broiler Management Handbook. Aviagen Inc., Huntsville, AL, USA.

Baillie, A. G. and P. J. Garlick. 1991. Responses of protein synthesis in different skeletal muscles to fasting and insulin in rats. Am. J. Physiol. 260: E891-E896.

Brown-Borg, H. M. and A. Bartke. 2012. GH and IGF1: roles in energy metabolism of long-living GH mutant mice. J. Gerontol. A. Biol. Sci. Med. Sci. 67A:652-660.

Cai, L., Y. S. Park, S. I. Seong, S. W. Yoo, and I. H. Kim. 2015. Effects of rare earth elements-enriched yeast on growth performance, nutrient digestibility, meat quality, relative organ weight, and excreta microflora in broiler chickens. Livest. Sci. 172:43-49.

Carbajal, D., V. Molina, S. Valdes, L. Arruzazabala, I. Rodeiro, R. Mas, and J. Magraner. 1996. Possible cytoprotective mechanism in rats of $\mathrm{D}-002$, an anti-ulcerogenic product isolated from beeswax. J. Pharm. Pharmacol. 48:858-860.

Castano, G., R. Mas, L. Feranadez, J. C. Fernandez, J. Illnait, L. E. Lopez, and E. Alvarez. 2000. Effects of policosanol on postmenopausal women with type II hypercholesterolemia. Gynecol. Endocrinol. 14:187-195.

Chikunya. S., G. Demirel, M. Enser, J. D. Wood, R. G. Wilkinson, and L. A. Sinclair. 2004. Biohydrogenation of dietary n-3 PUFA and stability of ingested vitamin $\mathrm{E}$ in the rumen, and their effects on microbial activity in sheep. Br. J. Nutr. 91:539550.

Crowley, M. A., W. T. Willis, K. S. Matt, and C. M. Donovan. 1996. A reduced lactate mass explains much of the glycogen sparing associated with training. J. Appl. Physiol. 81:362-367.

de Oliveira, A. M., L. M. Conserva, J. N. de Souza Ferro, F. de Almeida Brito, R. P. Lyra Lemos, and E. Barreto. 2012. Antinociceptive and anti-inflammatory effects of octacosanol from the leaves of Sabicea grisea var. grisea in mice. Int. J. Mol. Sci. 13:1598-1611.

Douris, P. C., B. P. White, R. R. Cullen, W. E. Keltz, J. Meli, D. M. Mondiello, and D. Wenger. 2006. The relationship between maximal repetition performance and muscle fiber type as estimated by noninvasive technique in the quadriceps of untrained women. J. Strength. Cond. Res. 20:699-703.

Gouni-Berthold, I. and H. K. Berthold, 2002. Policosanol: Clinical pharmacology and therapeutic significance of a new lipidlowering agent. Am. Heart. J. 143:356-365.

Hernandez, F., J. Illait, R. Mas, G. Castano, L. Fernandez, M. Gonzalez, N. Cordovi, and J. C. Fernandez. 1992. Effects of policosanol on serum lipids and lipoproteins in healthy volunteers. Curr. Ther. Res. 51:568-575.

Honikel, K. O. 1998. Reference methods for the assessment of physical characteristics of meat. Meat Sci. 49:447-457.

Kamboh, A. A. and W. Y. Zhu. 2013. Effect of increasing levels of bioflavonoids in broiler feed on plasma anti-oxidative potential, lipid metabolites, and fatty acid composition of meat. Poult. Sci. 92:454-461.

Kato, S., K. I. Karino, S. Hasegawa, J. Nagasawa, A. Nagasaki, M. Eguchi, T. Ichinose, K. Tago, H. Okumori, K. Hamatani, M. Takahashi, J. Ogasawara, S. Masushige, and S. Masushige. 1995. Octacosanol affects lipid metabolism in rats fed on a high-fat diet. Br. J. Nutr. 73:433-441

Kim, H., S. Park, D. S. Han, and T. Park. 2004. Octacosanol supplementation increases running endurance time and improves biochemical parameters after exhaustion in trained rats. J. Med. Food 6:345-351.

Lavery, G. G., E. A. Walker, N. Turan, D. Rogoff, J. W. Ryder, J. M. Shelton, J. A. Richardson, F. Falciani, P. C. White, P. M. Stewart, K. L. Parkers, and D. R. McMillan. 2008. Deletion of hexose-6-phosphate dehydrogenase activates the unfolded protein response pathway and induces skeletal myopathy. J. Biol. Chem. 283:8453-8461.

Liao, X. D., R. J. Wu, G. Ma, L. M. Zhao, Z. J. Zheng, and R. J. 
Zhang. 2015. Effects of Clostridium butyricum on antioxidant properties, meat quality and fatty acid composition of broiler birds. Lipids Health Dis. 14:36.

Long, L., M. Z. Gao, K. Peng, J. Sun, and S. X. Wang. 2015. Effects of octacosanol extracted from rice bran on production performance and blood parameters in weanling piglets. J. Chinese Cereals Oils Assoc. 30:94-100.

McCormick, R. J. 1999. Extracellular modification to muscle collagen: Implication for meat quality. Poult. Sci. 78:785-791.

Menendez, R., V. Fraga, A. M. Amor, R. M. Gonzalez, and R. Mas. 1999. Oral administration of policosanol inhibits in vitro copper ion-induced rat lipoprotein peroxidation. Physiol. Behav. 67:1-7.

Menendez, R., R. Mas, A. M. Amor, R. M. Gonzalez, J. C. Fernandez, I. Rodeiro, M. Zayas, and S. Jimenez. 2000. Effects of policosanol treatment on the susceptibility of low density lipoprotein (LDL) isolated from healthy volunteers to oxidative modification in vitro. Br. J. Clin. Pharmacol. 50:255262.

MAC (Ministry of Agriculture of China). 2004. Feeding Standard of Chicken. NY/T 33-2004. Standards Press of China, Beijing, China.

NRC (National Research Council). 1994. Nutrient Requirements of Poultry. 9th rev. edn. National Academy Press, Washington, DC, USA.

Ohta, Y., K. Ohashi, T. Matsura, K. Tokunaga, A. Kitagawa, and K. Yamada. 2008. Octacosanol attenuates disrupted hepatic reactive oxygen species metabolism associated with acute liver injury progression in rats intoxicated with carbon tetrachloride. J. Clin. Biochem. Nutr. 42:118-125.

Oliaro-Bosso, S., E. C. Gaudino, S. Mantegna, E. Giraudo, C. Meda, F. Viola, and G. Cravotto. 2009. Regulation of HMGCoA reductase activity by policosanol and octacosadienol, a new synthetic analogue of octacosanol. Lipids 44:907-916.

Pons, P., A. Jimenez, M. Rodrigues, J. Illnait, R. Mas, L. Fernandez, and J. C. Fernandez. 1993. Effects of policosanol in elderly hypercholesterolemic patients. Curr. Ther. Res. 53:265-269.
Qiao, X., H. J. Zhang, S. G. Wu, H. Y. Yue, J. J. Zuo, D. Y. Feng, and G. H. Qi. 2013. Effects of $\beta$-hydroxy- $\beta$-methylbutyrate calcium on growth, blood parameters and carcass qualities of broiler chickens. Poult. Sci. 92:753-759.

Saint-John, M. and L. McNaughton. 1986. Octacosanol ingestion and its effects on metabolic responses to submaximal cycle ergometry, reaction time and chest and grip strength. Int. Clin. Nutr. Rev. 6:81-87.

Scheele, C. W. 1997. Pathological changes in metabolism of poultry related to increasing production levels. Vet. Q. 19:127130

Shimura, S., T. Hasegawa, S. Takano, and T. Suzuki. 1987. Studies on the effect of octacosanol on motor endurance in mice. Nutr. Rep. Int. 36:1029-1038.

Singh, D. K., L. Li, and T. D. Porter. 2006. Policosanol inhibits cholesterol synthesis in hepatoma cells by activation of AMPkinase. J. Pharmacol. Exp. Ther. 318:1020-1026.

Taylor, J. C., L. Rapport, and G. B. Lockwood. 2003. Octacosanol in human health. Nutrition 19:192-195.

Xiang, Y., H. Yang, X. Wu, and J. P. Liu. 2012. Research and application progress of energy metabolism of body controlled by octacosanol. J. Xinxiang Univ. 29:44-46.

Xu, R. P. and H. Shen. 1997. Application of octacosanol in broilers diet. Feed Res. 5:26. (in Chinese)

Xu, Z. Y., E. Fitz, N. Riediger, and M. H. Moghadasian. 2007. Dietary octacosanol reduces plasma triacylglycerol levels but not atherogenesis in apolipoprotein E-knockout mice. Nutr. Res. 27:212-217.

Yang, H. 2012. The Preparation of Octacosanol and the Mechanism of the Impact on Energy Metabolism. M. Sc. Thesis, Changsha University of Science and Technology, Changsha, China.

Yu, C. Q. 2003. Study on damage of myocardial mitochondria in rats after exhaustive exercise. China Food Additives 2:35-37 (in Chinese).

Zhang, W. H., F. Gao, Q. F. Zhu, C. Li, Y. Jiang, S. F. Dai, and G. H. Zhou. 2011. Dietary sodium butyrate alleviates the oxidative stress induced by corticosterone exposure and improves meat quality in broiler chickens. Poult. Sci. 90:25922599 . 